\title{
Parental Influences on Children's Self-Regulation of Energy Intake: Insights from Developmental Literature on Emotion Regulation
}

\author{
Leslie A. Frankel, ${ }^{1}$ Sheryl O. Hughes, ${ }^{1}$ Teresia M. O'Connor, ${ }^{1}$ Thomas G. Power, ${ }^{2}$ \\ Jennifer O. Fisher, ${ }^{3}$ and Nancy L. Hazen ${ }^{4}$ \\ ${ }^{1}$ Children's Nutrition Research Center, Baylor College of Medicine, Houston, TX 77030, USA \\ ${ }^{2}$ Department of Human Development, Washington State University, Pullman, WA 99164, USA \\ ${ }^{3}$ Department of Public Health, Temple University, Philadelphia, PA 19140, USA \\ ${ }^{4}$ Department of Human Development and Family Sciences, The University of Texas at Austin, Austin, TX 78712, USA
}

Correspondence should be addressed to Leslie A. Frankel, lfrankel@bcm.edu

Received 4 November 2011; Accepted 11 January 2012

Academic Editor: Jutta Mata

Copyright (C) 2012 Leslie A. Frankel et al. This is an open access article distributed under the Creative Commons Attribution License, which permits unrestricted use, distribution, and reproduction in any medium, provided the original work is properly cited.

The following article examines the role of parents in the development of children's self-regulation of energy intake. Various paths of parental influence are offered based on the literature on parental influences on children's emotion self-regulation. The parental paths include modeling, responses to children's behavior, assistance in helping children self-regulate, and motivating children through rewards and punishments. Additionally, sources of variation in parental influences on regulation are examined, including parenting style, child temperament, and child-parent attachment security. Parallels in the nature of parents' role in socializing children's regulation of emotions and energy intake are examined. Implications for future research are discussed.

\section{Introduction}

Children's development of emotional self-regulation is important for many aspects of their health and wellbeing, including their ability to tolerate frustration [1], curb aggressive impulses [2], delay gratification [3], and express emotions in socially acceptable ways [4]. Children who are able to regulate their own emotions are better able to interact with their peers [5], whereas poor emotion regulation in preschool-aged children has been related to higher levels of externalizing behaviors [6-8]. Children's deficits in the ability to self-regulate their own behavior have been linked to rapid weight gain and obesity in middle childhood [9].

There is a strong body of evidence to support that parents play an important role in children's development of self-regulation of emotions in the early years $[7,10,11]$. At birth, infants lack control over their emotional arousal. Instead, infants' emotional arousal is regulated by their own biological needs and how parents respond to those needs.
Parents comfort infants when they express negative emotions as well as arouse positive emotions in their infants through play and other stimulating interactions [12]. For example, if a one-month-old infant experiences an aversive stimulus, the infant's crying signals to the parent that he or she is upset. Parents' actions such as calming or soothing the infant serve to regulate the child's emotions. Therefore, young infants rely heavily on their parents to regulate their emotions. As children age, they require less assistance in regulating emotions. For example, a four-year-old might self-sooth in response to an aversive stimulus instead of immediately crying.

Children's self-regulation of energy intake refers to children's ability (inborn and socialized) to eat and not eat in response to cues of hunger and satiety [13]. The development of self-regulation of energy intake in childhood is important for many aspects of health and wellbeing. Notably, overweight children have been found to have deficits in self-regulation of energy intake compared to normal weight peers $[14,15]$. Researchers have demonstrated that preschool 
children are capable of self-regulation of energy intake [16, 17]. At the same time, large individual differences in children's self-regulation of energy intake have been found. Temple and colleagues found food to be more reinforcing for overweight children than for normal weight children [18]. Additionally, fMRI studies have demonstrated greater anticipatory and consummatory reward responses in brain regions of overweight adolescents compared to normal weight adolescents [19]. To the extent that individuals are motivated by external cues, they may be less sensitive to internal signals of hunger and less able to self-regulate their energy intake in the presence of external food cues. Given that socialized (non-inborn) aspects of self-regulation of energy intake develop in the context of parent-child interactions during feeding with parents, parents are likely to play an important role in the development of such individual differences. A small but growing body of research is indicating that this is the case; individual differences in parents' feeding practices have been linked to individual differences in children's selfregulation of energy intake [20-24]. At the same time, there are gaps in our knowledge of how parents influence children's development of self-regulation of energy intake.

There is a large body of research on parental influences around emotion regulation, and this represents an exemplary model system for understanding parenting influences on children's development of self-regulation of energy intake. Thus, the literature on how parents influence children's emotion regulation can provide useful information for child obesity researchers concerning how parents may contribute to an obesogenic environment by influencing the development of children's self-regulation of energy intake. The purpose of this paper is to examine the literature on children's early development of emotion regulation, and in particular, parents' role in this development, to provide insight into the developmental processes by which parents influence children's self-regulation of energy intake.

\section{The Influence of Parents on Children's Self-Regulation of Emotions and Energy Intake}

Throughout the first year of life, infants gradually increase their ability to control their own emotional states $[25,26]$ and they begin to self-regulate emotions before the second half-year of life [27]. Individual differences in children's abilities to regulate their emotions are apparent by this time, and whether they intend to or not, parents substantially influence these individual differences [4].

Power [28] indentified some of the ways that parents can help children regulate their emotions. These parental techniques are relevant as infants progress through toddlerhood into their preschool years and beyond. They include (1) modeling emotion regulation or specific emotion regulation strategies; (2) responding to their children's emotional expression by acknowledging emotions, helping children process their emotions, helping children calm down, or questioning/punishing emotional expression; (3) assisting children in the moment by teaching them various emotion regulation strategies (e.g., attend to relevant stimuli, seek out appropriate information, analyze the situation, generate, and evaluate alternatives) and (4) motivating children through various social and material rewards and punishments [28]. This line of research on parental influences on children's self-regulation of emotions provides a useful framework that researchers interested in parental influences on children's self-regulation around food can utilize. For example, children experience both stress and hunger in the presence of their parents. Parents' reactions to children in these situations influence how children react to future experiences; therefore, how parents interact with their children influences children's self-regulation of both emotions and eating. The following discussion of each of these parenting processes shows how the literature on parental influences on children's emotional regulation can inform our understanding of the impact of parents' behaviors on children's self-regulation of energy intake.

2.1. Parental Modeling. Parents may not be aware of it, but they model behaviors around both emotional expressivity and food intake beginning when their children are infants. The literature on self-regulation of emotions indicates that parents provide very important models by which children learn to express emotions and later learn to control emotional expressivity. For example, researchers have found that infants in their first half-year of life mimic the emotions of their parents $[2,6,29]$. When parents display a wide range of positive and negative emotions in appropriate social contexts, their children are more likely to learn which emotions are appropriate to display in which situations; conversely, when parents display high levels of anger or personal distress, children are less likely to observe and learn appropriate ways to regulate and express their negative emotions [30].

Similarly, parents can provide both positive and negative models of self-regulation of energy intake through their own eating practices. For example, researchers have found that parents report that they often eat foods during meals that they would like their child to eat [31]. However, parents' modeling behaviors may either be conducive or not conducive to children developing good self-regulation of energy intake. After being asked if they want seconds, parents who respond by saying that they are full provide a positive model to their child. However, parents who say they are "stuffed" but then ask for dessert may provide negative models. To this point, Johnson and Birch found parental selfreport of disinhibited eating was correlated with children's lessened ability to self-regulate energy intake [20]. It may be that parents who report disinhibited eating are providing negative models of self-regulation of energy intake, thereby setting forth the pathway to poor self-regulation of energy intake in their children. Although, to our knowledge, most of the literature on modeling and energy-intake deals with food acceptance [31], and little-to-no work has been conducted on parent modeling and self-regulation of energy intake with children. Some research has been conducted on peer modeling and energy intake in children. Notably, Salvy et al. found differences in the amount of food consumed by overweight and normal weight children when alone and with 
peers. Overweight children consumed more when in solitude than when in the presence of peers [32]. As discussed by the authors, one possible reason for the lessened amount consumed in the presence of peers for overweight children is that normal weight children were modeling lower energy intake amounts and overweight children modified their intake amounts accordingly when in the presence of normal weight peers [32]. Researchers interested in understanding parental contributions to children's self-regulation of energy intake should further examine how parents model behaviors around their own regulation of energy intake and the influence of these parental behaviors on children.

2.2. Parental Responses to Children's Behavior. Research in the area of emotional expressivity indicates that the specific ways in which parents respond to children's emotions, beginning in infancy and continuing throughout early childhood, are influential in shaping children's self-regulation of emotions. Parents' acceptance of positive and negative emotions is important for optimal development of emotional expression and emotional regulation because children whose parents are accepting of their negative and positive emotions feel free to express both types of emotions when distressed and are better able to eventually express these emotions in socially accepted ways [7, 33, 34]. Parental responses to their children's negative emotions should also be contingent on children's behavior, as well as appropriate given the child's behavior, age, and needs (see Black and Aboud for review of responsive parenting) [35-38]. In contrast, the parental practice of over-control around emotions occurs when parents respond in punitive, distressed, or minimizing ways to children's expressions of negative emotions $[13,14]$. Punitive responses include anger or threats, for example, "Stop that crying or I will give you something to cry about." Minimizing responses are those that fail to validate the child's emotions by belittling them, for example, "Oh, you're being a baby." Distressed responses are those in which parents respond to their children's negative emotions by displaying distressed negative emotions themselves (e.g., a frustrated or angry vocal tone). All of these responses show a lack of acceptance of the child's emotion and do not help the child learn to deal with that emotion in a productive way. Parental overrestriction of emotional expressivity has been linked to children's lessened capacity to regulate their own emotions and thus to undesirable outcomes for children [39].

Research has indicated that negative parent reactions to children's negative emotions can have one of two possible outcomes. First, they can ultimately result in greater negative emotional expressivity in children since the children become frustrated with having to continually suppress their emotions [11, 40]. For example, researchers have found that school-aged children whose parents react in more punitive ways to their negative emotions have deficits in their ability to regulate emotion and express higher levels of externalizing behaviors based on teacher reports [6-8]. The second possible outcome is that some children succeed in suppressing their negative emotions, leading to flat emotional expressivity (suppression of both negative and positive emotions), and possibly to later internalizing problems [11].
Similarly, parental responses to children's expressions of hunger and satiety cues are likely to be important influences in shaping their children's self-regulation of energy intake. Parents can respond to children's cues in ways that encourage optimal self-regulation of energy intake (e.g., letting children leave the table when they say they are full, encouraging children to reflect on how full they are before they are served some more, encouraging children to slow down the rate of eating) or in ways that interfere with self-regulation of energy intake (e.g., refusing to believe children's statements about fullness and encouraging them to eat more). Just as parental restriction of children's emotional expressivity has been thought to interfere with children's ability to self-regulate their own emotions, parental restriction around food has been linked to deficits in self-regulation of energy intake in children [24]. Parental restriction around food occurs when parents overly restrict the quantities and types of foods available for the child to eat [41]. Findings from a laboratory assessment of satiety in children suggest that children whose parents reported more restrictive and controlling feeding behaviors ate more beyond satiety compared to their peers $[42,43]$. Thus, researchers interested in the development of children's self-regulation of energy intake should examine over-restriction of foods parents make available to children as well as overcontrol of the amount of food children can eat as a possible mechanism for children developing less than optimal self-regulation of energy intake. Additionally, researchers should further look into different types of control that parents use (i.e., overt control and covert control) [44] and the reasons why parents restrict foods (i.e., restriction for health and restriction for weight) [45]. Children who experience too much parental control around eating may not learn to identify their own satiety cues and thus may have poor abilities to self-regulate their energy intake. To this point, researchers have found associations between controlling parent feeding practices (as assessed by survey measures) and children's lessened ability to self-regulate energy intake [20]. Thus, as parental overcontrol of young children's emotional expressivity results in children not learning adaptive ways of expressing emotions (either over- or underregulating their emotions), parental over-restrictiveness around food may diminish children's ability to read their own hunger and satiety cues and respond with appropriate self-regulation of energy intake. Some children may thus overeat when parents are not present to monitor their eating, and others may undereat.

In addition to affecting the development of their children's abilities to self-regulate energy intake through controlling their children's food intake or access to certain foods, parents may also affect their children's energy intake through the ways in which they respond to children's emotions surrounding food. Parents present infants with new textures, tastes, and temperatures during meals. This can elicit frustration, sadness, and even anger from children, who, in turn, can also frustrate and anger the parents, altering the emotional context of the meal altogether. This is an important process for researchers interested in self-regulation of energy intake to better understand because parental responses to children's negative emotions around food have the potential to influence the child's view of that particular food or the 
process of eating in general. For example, if a parent responds with anger or frustration to the child's refusal to eat spinach, this response may serve to increase the emotionally negative quality of spinach for the child. Similarly, if having sweets is always associated with emotionally happy occasions like holidays or birthdays, this would increase the emotionally positive quality of sweets.

2.3. Parental Assistance in Helping Children Self-Regulate. According to Gottman et al., parents who engage in "emotion coaching" are highly aware of their children's emotions, they are accepting of their children's emotions (positive and negative) and assist them in the process of understanding their emotions and expressing their emotions in socially appropriate ways [11]. A parent might engage in emotioncoaching by saying, "I can see you are angry and it is OK to be angry. You cannot scream in here. Take a deep breath and use your words to tell me what is wrong." These techniques used by parents have been associated with better self-regulation of emotions in children [8]. These findings have great potential to inform researchers interested in understanding parental influences on children's ability to self-regulate energy intake. Parents can assist children in the process of self-regulation of energy intake by helping them attend to relevant stimuli (e.g., appropriate portion size, internal fullness, or hunger cues), encouraging them to seek out appropriate information (e.g., reading and understanding food labels), and generating and evaluating alternatives (e.g., considering options when they are hungry for a snack). Theoretically, parents can engage in intake-coaching by understanding and accepting their children's cues of hunger and satiety and assisting their children with making appropriate choices about the types and amounts of foods that they consume. It is important for parents to assist children with appropriate choices. For example, if choosing from a children's menu, parents can present their children with a few acceptable choices instead of the entire menu. Additionally, given that portion sizes have increased in recent years [46], parents can control the amount of food presented to children when out at restaurants by modifying portions on their children's plates before they begin eating. This can be accomplished through splitting large portioned meals between two children or packaging some food as leftovers before beginning a meal. Researchers should investigate whether these parental practices of intake-coaching, a concept similar to scaffolding energy intake, foster better self-regulation of energy intake in children.

\subsection{Motivating Children through Rewards and Punishments.} As noted above, punitive parental responses to children's expression of negative emotion have negative consequences for children's emotion regulation. Much of the time, parents respond to children's emotions with no conscious intent to socialize them, such as when they show frustration and distress themselves when their children cry. Often, however, parents consciously try to motivate their children to suppress their display of negative emotions by threatening punishment or offering rewards. These practices do suppress the expression of emotion in the immediate situation. However, when this is a common practice, children are less likely to learn how to productively deal with their negative emotions $[11,40]$.

Similarly, some parents may try to motivate self-regulation of energy intake through external rewards and punishments. Experiments have indicated better ability to selfregulate energy intake in children who have been encouraged by caregivers to pay attention to internal cues of hunger and satiety rather than external cues such as rewards [21]. Rewards tend to increase the amount of a food consumed, however, evidence suggests that they might also undermine children's natural intrinsic motivation to eat that particular food (see Cooke and colleagues [47] for a review). Birch and colleagues found that children who were instructed to finish their meals before receiving a reward consumed more after preload than their same-aged peers who had been instructed to pay attention to internal cues of fullness [48]. Their experiment was meant to simulate the real-life condition in which parents require children to clean their plate before engaging in a desired behavior. For example, a parent might say, "Jimmy, you can go play with your sister once you finish your chicken and broccoli." It has been theorized that contingency-based parent behaviors such as this impair children's ability to self-regulate their energy intake. Punishments are likely to be counterproductive because they are likely to override sensitivity to internal cues of fullness and hunger.

Additionally, parents often comfort children with food [49]. For example, some children receive a lollipop as a reward for enduring a shot at the doctor's office. Although this is a mundane example, it is a demonstration of how two things that are not at all related (emotional/physical pain and candy) can become related over time. Later in life, people who find comfort in food because of childhood experiences, might be more likely to turn to a pint of ice cream to cope with a breakup or a candy bar as a pick-me-up after getting reprimanded by their boss. Although parental reports of providing food as comfort have not been associated with overweight status in children $[50,51]$, high parental use of this technique has the potential of teaching children to rely on food to cope with difficult emotions or stress and may influence energy intake over time and should be further investigated by researchers. Additionally, parents may be less likely to admit using food to comfort their children on selfreport measures or may not even be aware if they do this often. Thus, more observational studies of feeding behavior in the home would be useful.

\section{Sources of Variation in Parental Influences on Children's Emotion Regulation and Energy Intake}

Studies examining parental influences on children's emotion regulation have examined the role of numerous sources of variation that relate to parent-child interaction patterns relevant to children's development of healthy patterns of emotional self-regulation. These sources of variation have included variations in parenting (e.g., parenting style), variations in children (e.g., the child's inborn temperament), and 
variations in the parent-child relationship (e.g., child-parent attachment security). We next explore implications of these sources of variation for the development of children's energy intake.

3.1. Parenting Style. Parenting styles are a useful way to examine constellations of parenting behaviors. Parenting styles are relevant to self-regulation of both emotions and eating because, as Rhee suggested, they can be looked at as the "emotional background" in which parenting practices take places (page 23) [52]. Although parenting styles were first conceptualized by Baumrind [53], scholars further elaborated these styles using dimensions of demandingness and responsiveness [54]. Parents with an authoritative style are highly demanding and highly responsive, those with an authoritarian style are highly demanding and low in responsiveness, those with an indulgent style are highly responsive but low in demandingness, and those with an uninvolved style are low in both.

The authoritative style presents an optimal context for fostering children's self-regulation in many situations since authoritative parents are more likely than other parents to model positive and socially appropriate emotional responses to frustrating situations and to provide adaptive emotional coaching [55]. In contrast, authoritarian parents are more likely than other parents to model undercontrolled, angry emotions in frustrating situations and to respond in a punitive fashion to their children's expression of negative emotions [55].

These parenting styles have also been hypothesized to be relevant for explaining differences in children's self-regulation of energy intake. Rhee [52] suggested that researchers look at feeding behaviors that authoritative parents engage in because these are likely the most effective for children's health and well-being. Authoritative parents might require that their children finish their meatloaf and peas before playing with their toys but give into their children's needs when he or she expresses that they cannot eat any more food; for example, they might change their request such that their child eat some of the meatloaf and peas rather than all. This would be conducive to children developing good self-regulation around eating because it would encourage them to pay attention to their own internal cues of hunger and fullness. Additionally, parents responding to children's cues of hunger and fullness should empower children to self-regulate energy intake instead of energy intake being regulated solely by parents. In contrast, it is unlikely that authoritarian parents would be responsive to children's negative emotions around food or children's requests to eat or not eat due to feelings of hunger or fullness. Given what is known in the literature related to emotion regulation, parental lack of responsiveness to children's cues of hunger and satiety paired with parents being demanding might result in a flattening of these cues and, as a result, be detrimental to self-regulation around eating in children of authoritarian parents.

In support of these ideas, findings of a study that examined the relation of the four parenting styles to the overweight status of first-grade children indicated that children with authoritarian mothers were at the highest risk for being obese, whereas children with authoritative mothers were at the least risk [56]. Similarly, adolescents with authoritative parents were significantly more likely to consume fruit and to have positive attitudes toward fruit consumption than those with authoritarian parents [57]. It is important for researchers to look further into the relation between parenting style and children's overweight status to examine whether children's self-regulation of energy intake does in fact mediate this association.

Researchers have found some interesting differences across ethnicities in regards to how parenting styles relate to child outcomes. For example, in contrast with the typical research findings that children of authoritative parents have better outcomes, Tamis-LeMonda et al. found that authoritarian parenting styles were associated with positive child outcomes in low-income African-American families [58]. Given that this research was done among only one economic strata of African-American families, researchers do not yet know if these findings are due to differences in culture, income, or both [58]. Hughes and colleagues found a similar relationship between feeding styles and weight status; their studies suggest a negative relationship between authoritarian feeding styles and weight status in low-income, ethnically diverse samples $[59,60]$. Understanding findings across low income samples of children is especially important given that, in the United States, people of low SES have a higher rate of obesity than people who are not low SES [61].

Highly permissive parenting (including both indulgent and uninvolved) has also been linked with young children's poor emotion regulation and aggressive behavior [62], indicating that parents' sensitive responsiveness alone is not sufficient for children's development of optimal emotion regulation. Permissive parents may be less likely than authoritarian parents to scaffold their children's development of healthy emotional regulation by modeling appropriate emotional expressivity and providing "emotion-coaching." Similarly, they may be less likely to provide children with the motivation and guidance needed to help them develop effective selfregulation of energy intake.

In support of this idea, Rhee and colleagues found that indulgent and uninvolved parents were twice as likely as authoritative parents to have overweight children, though these children were at less risk than those with authoritarian parents [56]. However, Hughes and colleagues found in a low-income sample, parents' use of indulgent feeding styles actually predicted the greatest risk for childhood obesity, even greater than the authoritarian feeding styles [59]. Parents who engage in indulgent feeding place few demands on their children's eating behavior, although the few demands they do make are nondirective and supportive. It is possible that these children lack the scaffolding provided by authoritative and authoritarian parents to help teach self-regulation of energy intake. Again, research on whether or not self-regulation of energy intake and low parental scaffolding mediate the relationship between indulgent parenting/feeding and higher child BMI is needed.

Hughes and colleagues did not find differences in children's energy intake as a function of parents having an uninvolved style of parenting. The authors reasoned that 
uninvolved parents should be unlikely to foster self-regulated eating habits in their children; although not measured in their study, they also speculated that uninvolved parents may provide a generally poor diet for their children. Future research on the feeding patterns of uninvolved parents is needed $[60]$.

3.2. Child Temperament. Self-regulation of emotions and energy intake are both likely to be influenced by children's inborn traits. Although temperament is defined as a stable and enduring trait [63], the behavioral manifestations of infants' temperament are modified over time as a consequence of repeated interactions with parents and others. Thus, some researchers have studied temperament from a more developmental, cyclical perspective to better understand how infants' inborn temperament influences their development of emotion self-regulation. For example, Thompson approached the subject of parental influence on children's self-regulation of emotion from a bidirectional point of view; he argued that both intrinsic components (e.g., temperament) and extrinsic components (e.g., parental socialization) are involved in the development of emotional regulation. That is, although it has been demonstrated that temperament can be influenced by environment, the child's temperament can also influence the way that people react to the child [12]. According to Cassidy, "When an infant's strategic response to a mother's caregiving is considered, two contributions of temperament are acknowledged: (a) the response is likely to fall within a range that is constrained by the infant's temperament and (b) infants are not only responsive to their mother's caregiving behavior but also contribute to shaping its nature" (page 244) [33].

Infants are born with different levels of emotional reactivity that influence their care-giving environment [64]. People often refer to highly reactive infants as fussy or difficult and infants who are not reactive as easygoing. A fussy baby might elicit more frustration from his or her caregiver than an infant who rarely cries. Additionally, a fussy baby might elicit a different response from his or her caregiver upon crying than an infant who rarely cries. According to the dynamic viewpoint of temperament posited by Thompson, Cassidy, and others, the difference in quantity or quality of caregiver response to the infant's emotional expressivity has the potential to shape the infant's subsequent emotional expressivity. In turn, the way the infant comes to express emotions elicits further emotional socialization from the parent [65]. Thus, a fussy infant might elicit greater expression of personal distress from a parent, which may increase the infants' negative emotionality over time, whereas another parent who responds to the infants' crying with comforting may decrease the infants' negative emotionality.

Borrowing from the literature on the development of self-regulation of emotions, it is evident that temperament is likely to be an important factor in the cyclical process of how interactions with parents influence children's self-regulation of energy intake. For example, parents may be more tempted to use foods to comfort and sooth infants and children who have more difficult temperaments, and the parent-child interactions surrounding foods are likely to be more stressful for infants with highly reactive temperaments compared to infants who are more easily soothed. Some research evidence for this exists. Agras and colleagues found child temperament to mediate the relationship between parent overweight and child overweight. Specifically, children of overweight parents who were rated as highly emotional in the Children's Behavior Questionnaire [66] were more than twice as likely to be overweight at 9.5 years than children of overweight parents who were not highly emotional [67]. However, specific ways in which temperament influences interactions between children and their parents around food are not well known. Therefore, researchers interested in the developmental processes by which parents influence children's self-regulation of energy intake should take child temperament into account.

3.3. Child-Parent Attachment. Research about the influence of attachment on children's interactions with their parents and children's subsequent self-regulation of emotions is also likely to have important implications for understanding the relation between children's attachment and self-regulation of food intake. Based on their caregivers' history of success in providing comfort and protection to their infants when they are distressed, infants have expectations as to how their caretaker will react to future expressions of distress and form strategies based on these expectations that they will use later when distressed in order to seek comfort from their caregivers. These individual differences in the strategies that infants use to gain comfort from their caregivers can be seen in the Strange Situation Paradigm, the classic method of assessing security of infant-caregiver attachment [68]. After entering an unfamiliar room with their caregiver, secure infants explore the room freely when their caregiver is present, using the caregiver as a secure base. Security of attachment is assessed primarily as a function of infants' behavior during reunions, after being separated from their caregiver. If securely attached infants become distressed during separations, they immediately seek proximity to the caregiver upon reunion and are calmed easily by their caregiver, and if not distressed, they still show accepting behavior towards their caregiver in reunion episodes and clearly prefer the caregiver over the stranger. In contrast, infants classified as insecure-avoidant show less distress during separation and turn away from the caregiver upon reunion, and those classified as insecure-ambivalent cannot be comforted. They show ambivalence toward the caregiver, mixing clinging, and proximity-seeking behavior with displays of anger, such as hitting.

Cassidy has proposed that individual differences in children's emotion regulation can be predicted from their attachment histories [33]. Numerous studies have found that parents of securely attached infants are more likely than those of insecure infants to respond to them with sensitivity [69]. Because of this, Cassidy [33] hypothesized that children with secure attachment histories should develop healthier patterns of flexible emotion regulation than those with insecure histories. Particularly, since their mothers have been more likely to respond in a sensitive way to their emotional cues, secure infants should be more likely to express both negative and positive emotions in a healthy way by neither 
suppressing nor heightening their emotional expressivity, but rather, expressing both in appropriate contexts.

In contrast, children with insecure-avoidant attachment histories are hypothesized to suppress their expression of negative emotions, becoming emotionally overregulated since their mothers have generally rejected their expression of negative emotions during the course of their early development [33].

Results of several studies support the idea that caregivers of insecure-avoidant infants inadvertently socialize them to minimize their emotional expressivity, leading to emotional overregulation. For example, these infants had been found to approach their mothers in the "Strange Situation" primarily when calm and contented rather than when distressed [70, 71], even though heart-rate measures indicated that they were actually more physiologically distressed by separations than were secure babies. Avoidantly-attached infants have also been found to use self-soothing behaviors such as thumb sucking when distressed more often than other infants do [72]. In toddlerhood, children with avoidant attachment were found to be more likely than other children to show flat affect during stressful situations, indicating suppression of negative emotions [73]. Interestingly, however, avoidantly attached preschoolers have been found to more angry and aggressive with peers than secure children in childhood [74] and adolescence [75]. It may be that avoidantly attached children generally try to suppress their negative emotion, but continual suppression of negative emotion may lead to frustration and, ultimately, to poor emotional regulation later in development.

At the other end of the spectrum, children with insecureambivalent attachment histories are expected to become emotionally underregulated since their mothers have been likely to respond inconsistently, especially when these infants are distressed [76]. As a result of this history of maternal lack of consistency, these infants maximize attachment behaviors when distressed; that is, they become clingier, and they cry and fuss more to get the caregiver's attention [77]. Some evidence also supports the idea that caregivers of insecureambivalent infants inadvertently socialize them to maximize their expression of fearful negative emotions. For example, ambivalent infants show more fear and cry more in laboratory procedures during infancy [78] and toddlerhood [79], and as preschoolers, these children are more fearful when exploring a new environment [80] and when interacting with peers [81].

Since insecure attachment is related to children's poor emotion regulation, it may also be related to children's poor regulation of energy intake and thus be a risk factor for childhood obesity. In one of the only studies that has examined the relation between attachment and obesity, Anderson and Whitaker [82] argued that since insecure attachment is related to children's poor emotion regulation, it may be a risk factor for childhood obesity. They reasoned that emotion regulation should be related to obesity since poorly regulated children experience greater stress, and the stress response has been linked to obesity $[83,84]$. In addition, problems with regulating negative emotions such as fear, sadness, and anger have been found to predict eating in the absence of hunger and disinhibited eating $[85,86]$. Using the large national sample from the Early Childhood Longitudinal Study, Anderson and Whitaker found that insecure attachment, assessed at 24 months of age, predicted an increased risk of childhood obesity at age 4.5 years. This was found even after controlling for potentially confounding variables, including the quality of mother-child interaction, parenting practices related to obesity (e.g., having regular family dinners, duration of breastfeeding, television/video viewing time, etc.), maternal health and BMI, and SES [82].

However, this study did not investigate mechanisms that might explain the link between insecure attachment and an increased risk of obesity. The researchers suggested that poor emotion regulation mediates this relationship, but children's emotion regulation was not assessed. Moreover, different types of insecure attachment (avoidant versus ambivalent) might affect children's emotion regulation in different ways. Since both over- and underregulation of emotional expression are nonoptimal emotion regulation strategies, both types of insecure attachment may increase the risk of obesity by increasing children's physiological stress. However, if disinhibited eating, rather than stress, is the key mediator of the relation between insecure attachment and obesity, and if disinhibited eating is related to emotional underregulation, it may be that anxious-ambivalent children are at particularly high risk for obesity. In a cross-sectional study done with adults, disinhibited eating was found to mediate the relation between anxious attachment style (analogous to insecure-ambivalent attachment style in infancy) and higher adult BMI. However, avoidant attachment was unrelated to both disinhibited eating and having a higher BMI [87]. Longitudinal studies are needed that directly examine children's stress reactions and disinhibited eating as possible mediators of the relation between both types of insecure attachment and obesity.

In addition, future research should investigate whether parent-child attachment security relates to differences in the ways that parents feed their children and socialize their eating habits. Since research has found strong links between infants' attachment security and parental sensitivity [88-90], it may be that parents of insecure infants are less sensitive in interactions surrounding food. For example, they may be more controlling or restrictive during such interactions, which may in turn lead to an increased risk for obesity.

\section{Summary}

Obesity is increasing in children at epidemic rates [91] with one-third of children in the United States currently overweight or obese [92]. Given that increases in childhood obesity are not fully explained by genetics alone, researchers need to concentrate on the obesogenic environment of children including factors in the family environment. As evidenced thus far, parents are key figures in socializing their children's behaviors and self-regulation of energy intake. However, little is known about the developmental process by which parents influence children's self-regulation of energy intake. Researchers interested in this process can learn from 
the large body of research on how parents influence children's regulation of emotions.

This research provides important insights regarding how parents might influence children's development of self-regulation of energy intake and how variations in parenting, child temperament, and the parent-child relationship might affect this. To date, research examining the relation of parenting to children's overweight status has found links between children's overweight status and the ways that parents respond to their children's eating, particularly in terms of restricting or controlling children's food intake and the use of rewards and punishments to do this. However, whether or not children's energy intake mediates the relationship between food parenting practices and children's overweight status has rarely been examined directly. In addition, the role of parental modeling and parental coaching in the development of children's self-regulation of energy intake has rarely been studied. Future studies should include more observational research of parent-child interactions surrounding food since parents may underestimate their use of particular food parenting strategies, such as the use of sweets as a reward. Parents also may be unaware of their emotional responses to children's eating behaviors or of the ways they might coach children's self-regulation of energy intake.

Parents' socialization of children's eating behaviors (including modeling, responding to children's eating behaviors, coaching, and using rewards and punishments) is likely to change over time in response to developmental changes in their children's self-regulation of eating and their children's subsequent eating behaviors. Thus, longitudinal studies are needed to examine bidirectional relationships between food parenting practices, children's self-regulation, children's eating behaviors, and children's overweight status over time. Longitudinal studies are also important for examining the role of how moderating factors such as parenting styles, child temperament, and parent-child attachment affect the relation between food parenting practices and children's selfregulation of energy intake. To date, most studies have not gone beyond simply finding relations between these factors and children's overweight status; for example, insecure attachment has been found to be related to increased risk of child obesity [82]. Some of the research on parenting styles has gone further, finding relations between parenting styles, particular kinds of parental feeding practices, and children's overweight status over time [56]. In discussing the results of these studies, obesity researchers have often speculated that children's self-regulation of energy intake may mediate these associations, but research specifically investigating children's self-regulation of energy intake as a mediator that may explain the relation of food parenting practices and children's overweight status is lacking.

Whereas researchers in the area of self-regulation of energy intake have many opportunities to learn from the literature on self-regulation of emotions, it is also important to note that the two domains do not function independently; instead, there are a variety of overlapping contexts in which food and emotions exist. Food influences emotions and emotions influence peoples' behaviors when eating food [93]. Similarly, eating is often an emotional experience. In this sense, there is an interesting intersection between food and how emotions are regulated. For this reason, researchers interested in the role of self-regulation of energy intake in childhood obesity should conduct assessments of children's general self-regulation as well as self-regulation of energy intake to see if the two are related.

Future research should also examine the role of the broader economic and cultural context on how parents influence children's development of self-regulation of energy intake. According to Bronfenbrenner's ecological model of development, parent-child interactions are nested within larger socioeconomic and cultural contexts and cannot be fully understood apart from these larger contexts [94]. Parenting in low-SES samples differs from parenting in middleand upper-income samples in a multitude of ways, including types of maternal employment, single-mother families, and lower maternal education [95]. One key factor likely to be relevant to parents' influence on children's self-regulation of both emotions and energy intake is the high degree of stress present in low-SES environments. Stress has been found to have a substantial impact of parenting, as it has been related to more insecure attachment [96] and a greater use of authoritarian parenting practices [97]. Also, as noted previously, the relation of different parenting styles to child outcomes varies according to SES and cultural differences [58]. Low-income parents are also more likely to experience food insecurity, which may affect food parenting. For example, food insecurity has been associated with maternal reports of using compensatory feeding practices, that is, giving children extra food or more energy-dense foods such as soda [98]. Low-income families are also more likely to serve calorie-dense fast foods and processed foods to their children since they are less expensive than fresh fruits and vegetables, as well as more filling [99]. Additionally, low-income parents might be more likely to give their children calorierich "comfort" foods to help them deal with stress since low-income families face more economic stress and stressful life events [60]. Finally, different ethnic groups are likely to have different culturally based customs regarding serving and eating food. For example, Hispanic mothers have been found to use a more indulgent feeding style in several studies, granting most of their children's requests for food $[60,100]$.

Although it is common for researchers interested in selfregulation of energy intake to assess children's ability to regulate energy intake with children alone, the process by which parents influence children's development of self-regulation is important; therefore, researchers interested in parental contributions to the development of children's selfregulation of energy intake should study it within the context of parent-child relationships. Multidisciplinary teams of researchers with knowledge of nutrition and physiology should collaborate with developmental psychologists in order to fully understand the complex process by which parents influence children's self-regulation of energy-intake.

\section{Conflict of Interests}

The authors declare that they have no competing interests. 


\section{Acknowledgments}

This research was supported by funds from R01 HD062567. This work is a publication of the United States Department of Agriculture (USDA/ARS) Children's Nutrition Research Center, Department of Pediatrics, Baylor College of Medicine, Houston, Texas, and had been funded in part with federal funds from the USDA/ARS under Cooperative Agreement no. 58-6250-0-008. The contents of this publication do not necessarily reflect the views or policies of the USDA nor does mention of trade names, commercial products, or organizations imply endorsement from the U.S. government.

\section{References}

[1] L. J. Bridges LJ and W. S. Grolnick, "The development of emotional self-regulation in infancy and early childhood," in Social Development, N. Eisenberg, Ed., vol. 15 of Review of Personality and Social Psychology, pp. 185-211, Sage Publications, Thousand Oaks, Calif, USA, 1995.

[2] N. Eisenberg, R. A. Fabes, M. Nyman, J. Bernzweig, and A. Pinuelas, "The relations of emotionality and regulation to children's anger-related reactions," Child Development, vol. 65, no. 1, pp. 109-128, 1994.

[3] W. Mischel, Y. Shoda, and M. L. Rodriguez, "Delay of gratification in children," Science, vol. 244, no. 4907, pp. 933-938, 1989.

[4] L. H. Pollak and P. A. Thoits, "Processes in emotional socialization," Social Psychology Quarterly, vol. 52, no. 1, pp. 22-34, 1989.

[5] J. Cassidy, R. D. Parke, L. Butkovsky, and J. M. Braungart, "Family-peer connections: the roles of emotional expressiveness within the family and children's understanding of emotions," Child Development, vol. 63, no. 3, pp. 603-618, 1992.

[6] N. Eisenberg and R. A. Fabes, "Mothers' reactions to children's negative emotions: relations to children's temperament and anger behavior," Merrill-Palmer Quarterly: Journal of Developmental Psychology, vol. 40, no. 1, pp. 138-156, 1994.

[7] N. Eisenberg, R. A. Fabes, and B. C. Murphy, "Parents' reactions to children's negative emotions: relations to children's social competence and comforting behavior," Child Development, vol. 67, no. 5, pp. 2227-2247, 1996.

[8] R. A. Fabes, S. A. Leonard, K. Kupanoff, and C. L. Martin, "Parental coping with children's negative emotions: relations with children's emotional and social responding," Child Development, vol. 72, no. 3, pp. 907-920, 2001.

[9] L. A. Francis and E. J. Susman, "Self-regulation and rapid weight gain in children from age 3 to 12 years," Archives of Pediatrics and Adolescent Medicine, vol. 163, no. 4, pp. 297302, 2009.

[10] N. Eisenberg, A. Cumberland, and T. L. Spinrad, "Parental Socialization of Emotion," Psychological Inquiry, vol. 9, no. 4, pp. 241-273, 1998.

[11] J. M. Gottman, L. F. Katz, and C. Hooven, Meta-Emotion : How Families Communicate Emotionally, Lawrence Erlbaum Associates, Mahwah, NJ, USA, 1997.

[12] R. A. Thompson, "Emotion regulation: a theme in search of definition," Monographs of the Society for Research in Child Development, vol. 59, no. 2-3, pp. 25-52, 1994.

[13] R. F. Baumeister and K. D. Vohs, Handbook of Self-Regulation: Research, Theory, and Applications, Guilford Press, New York, NY, USA, 2004.
[14] S. Carnell and J. Wardle, "Appetite and adiposity in children: evidence for a behavioral susceptibility theory of obesity," American Journal of Clinical Nutrition, vol. 88, no. 1, pp. 2229, 2008.

[15] A. Jansen, N. Theunissen, K. Slechten et al., "Overweight children overeat after exposure to food cues," Eating Behaviors, vol. 4, no. 2, pp. 197-209, 2003.

[16] L. L. Birch and M. Deysher, "Caloric compensation and sensory specific satiety: evidence for self regulation of food intake by young children," Appetite, vol. 7, no. 4, pp. 323-331, 1986.

[17] L. L. Birch and M. Deysher, "Conditioned and unconditioned caloric compensation: evidence for self-regulation of food intake in young children," Learning and Motivation, vol. 16, no. 3, pp. 341-355, 1985.

[18] J. L. Temple, C. M. Legierski, A. M. Giacomelli, S. J. Salvy, and L. H. Epstein, "Overweight children find food more reinforcing and consume more energy than do nonoverweight children," American Journal of Clinical Nutrition, vol. 87, no. 5, pp. 1121-1127, 2008.

[19] E. Stice, S. Spoor, C. Bohon, M. G. Veldhuizen, and D. M. Small, "Relation of reward from food intake and anticipated food intake to obesity: a functional magnetic resonance imaging study," Journal of Abnormal Psychology, vol. 117, no. 4, pp. 924-935, 2008.

[20] S. L. Johnson and L. L. Birch, "Parents' and children's adiposity and eating style," Pediatrics, vol. 94, no. 5, pp. 653-661, 1994.

[21] L. L. Birch, L. McPheee, B. C. Shoba, L. Steinberg, and R. Krehbiel, "'Clean up your plate': effects of child feeding practices on the conditioning of meal size," Learning and Motivation, vol. 18, no. 3, pp. 301-317, 1987.

[22] L. L. Birch and J. O. Fisher, "Food intake regulation in children. Fat and sugar substitutes and intake," Annals of the New York Academy of Sciences, vol. 819, pp. 194-220, 1997.

[23] L. A. Francis, S. M. Hofer, and L. L. Birch, "Predictors of maternal child-feeding style: maternal and child characteristics," Appetite, vol. 37, no. 3, pp. 231-243, 2001.

[24] J. O. Fisher and L. L. Birch, "Restricting access to foods and children's eating," Appetite, vol. 32, no. 3, pp. 405-419, 1999.

[25] M. L. Diener and S. C. Mangelsdorf, "Behavioral strategies for emotion regulation in toddlers: associations with maternal involvement and emotional expressions," Infant Behavior and Development, vol. 22, no. 4, pp. 569-583, 1999.

[26] C. B. Kopp, "Regulation of distress and negative emotions: a developmental view," Developmental Psychology, vol. 25, no. 3, pp. 343-354, 1989.

[27] M. Lewis and C. Saarni, The Socialization of Emotions, Plenum Pr, New York, NY, USA, 1985.

[28] T. G. Power, "Stress and coping in childhood: the parents' role," Parenting: Science and Practice, vol. 4, no. 4, pp. 271317, 2004.

[29] N. Eisenberg, R. A. Fabes, G. Carlo, and M. Karbon, "Emotional responsivity to others: behavioral correlates and socialization antecedents," New Directions for Child Development, no. 55 , pp. 57-73, 1992.

[30] S. A. Denham, "Maternal emotional responsiveness and toddlers' social-emotional competence," Journal of Child Psychology and Psychiatry and Allied Disciplines, vol. 34, no. 5, pp. 715-728, 1993.

[31] T. Tibbs, D. Haire-Joshu, K. B. Schechtman et al., "The relationship between parental modeling, eating patterns, and dietary intake among African-American parents," Journal of 
the American Dietetic Association, vol. 101, no. 5, pp. 535$541,2001$.

[32] S. J. Salvy, J. S. Coelho, E. Kieffer, and L. H. Epstein, "Effects of social contexts on overweight and normal-weight children's food intake," Physiology and Behavior, vol. 92, no. 5, pp. 840846, 2007.

[33] J. Cassidy, "Emotion regulation: influences of attachment relationships," Monographs of the Society for Research in Child Development, vol. 59, no. 2-3, pp. 228-249, 1994.

[34] L. J. Berlin and J. Cassidy, "Mothers' self-reported control of their preschool children's emotional expressiveness: a longitudinal study of associations with infant-mother attachment and children's emotion regulation," Social Development, vol. 12, no. 4, pp. 477-495, 2003.

[35] M. M. Black and F. E. Aboud, "Responsive feeding is embedded in a theoretical framework of responsive parenting," Journal of Nutrition, vol. 141, no. 3, pp. 490-494, 2011.

[36] S. H. Landry, K. E. Smith, P. R. Swank, M. A. Assel, and S. Vellet, "Does early responsive parenting have a special importance for children's development or is consistency across early childhood necessary?" Developmental Psychology, vol. 37, no. 3, pp. 387-403, 2001.

[37] C. S. Tamis-LeMonda, M. H. Bornstein, L. Baumwell, and A. M. Damast, "Responsive parenting in the second year: specific influences on children's language and play," Infant and Child Development, vol. 5, no. 4, pp. 173-183, 1996.

[38] S. H. Landry, K. E. Smith, and P. R. Swank, "Responsive parenting: establishing early foundations for social, communication, and independent problem-solving skills," Developmental Psychology, vol. 42, no. 4, pp. 627-642, 2006.

[39] T. L. Spinrad, C. A. Stifter, N. Donelan-McCall, and L. Turner, "Mothers' regulation strategies in response to toddlers' affect: links to later emotion self-regulation," Social Development, vol. 13, no. 1, pp. 40-55, 2004.

[40] J. J. Gross and R. W. Levenson, "Emotional suppression: physiology, self-report, and expressive behavior," Journal of Personality and Social Psychology, vol. 64, no. 6, pp. 970-986, 1993.

[41] M. S. Faith, K. S. Scanlon, L. L. Birch, L. A. Francis, and B. Sherry, "Parent-child feeding strategies and their relationships to child eating and weight status," Obesity Research, vol. 12, no. 11, pp. 1711-1722, 2004.

[42] J. O. Fisher and L. L. Birch, "Eating in the absence of hunger and overweight in girls from 5 to $7 \mathrm{y}$ of age," American Journal of Clinical Nutrition, vol. 76, no. 1, pp. 226-231, 2002.

[43] L. L. Birch, J. O. Fisher, and K. K. Davison, "Learning to overeat: maternal use of restrictive feeding practices promotes girls' eating in the absence of hunger," American Journal of Clinical Nutrition, vol. 78, no. 2, pp. 215-220, 2003.

[44] J. Ogden, R. Reynolds, and A. Smith, "Expanding the concept of parental control: a role for overt and covert control in children's snacking behaviour?" Appetite, vol. 47, no. 1, pp. 100-106, 2006.

[45] D. R. Musher-Eizenman, S. C. Holub, J. C. Hauser, and K. M. Young, "The relationship between parents' anti-fat attitudes and restrictive feeding," Obesity, vol. 15, no. 8, pp. 20952102, 2007.

[46] C. Piernas and B. M. Popkin, "Increased portion sizes from energy-dense foods affect total energy intake at eating occasions in US children and adolescents: patterns and trends by age group and sociodemographic characteristics, 19772006," American Journal of Clinical Nutrition, vol. 94, no. 5, pp. 1324-1332, 2011.

[47] L. J. Cooke, L. C. Chambers, E. V. Añez, and J. Wardle, "Facilitating or undermining? The effect of reward on food acceptance: a narrative review," Appetite, vol. 57, no. 2, pp. 493-497, 2011.

[48] L. L. Birch, L. McPhee, B. C. Shoba, E. Pirok, and L. Steinberg, "What kind of exposure reduces children's food neophobia?. Looking vs. tasting," Appetite, vol. 9, no. 3, pp. 171-178, 1987.

[49] S. Carnell, L. Cooke, R. Cheng, A. Robbins, and J. Wardle, "Parental feeding behaviours and motivations. A qualitative study in mothers of UK pre-schoolers," Appetite, vol. 57, no. 3, pp. 665-673, 2011.

[50] S. Cornell and J. Wardle, "Associations between multiple measures of parental feeding and children's adiposity in United Kingdom preschoolers," Obesity, vol. 15, no. 1, pp. 137-144, 2007.

[51] J. Wardle and S. Carnell, "Parental feeding practices and children's weight," Acta Paediatrica, International Journal of Paediatrics, vol. 96, no. 454, pp. 5-11, 2007.

[52] K. Rhee, "Childhood overweight and the relationship between parent behaviors, parenting style, and family functioning," Annals of the American Academy of Political and Social Science, vol. 615, no. 1, pp. 12-37, 2008.

[53] D. Baumrind, "Current patterns of parental authority," Developmental Psychology, vol. 4, no. 1, pp. 1-103, 1971.

[54] E. Maccoby and J. Martin, "Socialization in the context of the family: parent-child interaction," in Handbook of Child Psychology, P. H. Mussen, Ed., Willey, New York, NY, USA, 1983.

[55] A. S. Morris, J. S. Silk, L. Steinberg, S. S. Myers, and L. R. Robinson, "The role of the family context in the development of emotion regulation," Social Development, vol. 16, no. 2, pp. 361-388, 2007.

[56] K. E. Rhee, J. C. Lumeng, D. P. Appugliese, N. Kaciroti, and R. H. Bradley, "Parenting styles and overweight status in first grade," Pediatrics, vol. 117, no. 6, pp. 2047-2054, 2006.

[57] S. P. J. Kremers, J. Brug, H. De Vries, and R. C. M. E. Engels, "Parenting style and adolescent fruit consumption," Appetite, vol. 41, no. 1, pp. 43-50, 2003.

[58] C. S. Tamis-LeMonda, R. D. Briggs, S. G. McClowry, and D. L. Snow, "Challenges to the study of African American parenting: conceptualization, sampling, research approaches, measurement, and design," Parenting, vol. 8, no. 4, pp. 319$358,2008$.

[59] S. O. Hughes, T. G. Power, J. Orlet Fisher, S. Mueller, and T. A. Nicklas, "Revisiting a neglected construct: parenting styles in a child-feeding context," Appetite, vol. 44, no. 1, pp. 83-92, 2005.

[60] S. O. Hughes, R. M. Shewchuk, M. L. Baskin, T. A. Nicklas, and H. Qu, "Indulgent feeding style and children's weight status in preschool," Journal of Developmental and Behavioral Pediatrics, vol. 29, no. 5, pp. 403-410, 2008.

[61] Y. Wang, "Cross-national comparison of childhood obesity: the epidemic and the relationship between obesity and socioeconomic status," International Journal of Epidemiology, vol. 30, no. 5, pp. 1129-1136, 2001.

[62] K. H. Rubin, P. Hastings, X. Chen, S. Stewart, and K. McNichol, "Intrapersonal and Maternal Correlates of Aggression, Conflict, and Externalizing Problems in Toddlers," Child Development, vol. 69, no. 6, pp. 1614-1629, 1998.

[63] M. Rothbart and D. Derryberry, Development of Individual Differences in Temperament, Lawrence Erlbaum Associates, Hillsdale, NJ, USA, 1981.

[64] R. A. Fabes, N. Eisenberg, M. Karbon, J. Bernzweig, A. Lee Speer, and G. Carlo, "Socialization of children's vicarious emotional responding and prosocial behavior: relations with 
mothers' perceptions of children's emotional reactivity," Developmental Psychology, vol. 30, no. 1, pp. 44-55, 1994.

[65] N. Eisenberg, R. A. Fabes, S. A. Shepard, I. K. Guthrie, B. C. Murphy, and M. Reiser, "Parental reactions to children's negative emotions: longitudinal relations to quality of children's social functioning," Child Development, vol. 70, no. 2, pp. 513-534, 1999.

[66] M. K. Rothbart, S. A. Ahadi, K. L. Hershey, and P. Fisher, "Investigations of temperament at three to seven years: the children's behavior questionnaire," Child Development, vol. 72, no. 5, pp. 1394-1408, 2001.

[67] W. S. Agras, L. D. Hammer, F. McNicholas, and H. C. Kraemer, "Risk factors for childhood overweight: a prospective study from birth to 9.5 years," Journal of Pediatrics, vol. 145, no. 1, pp. 20-25, 2004.

[68] M. D. Ainsworth, "Patterns of attachment," Clinical Psychologist, vol. 38, pp. 27-29, 1985.

[69] M. H. van Ijzendoorn, "Adult attachment representations, parental responsiveness, and infant attachment: a metaanalysis on the predictive validity of the adult attachment interview," Psychological Bulletin, vol. 117, no. 3, pp. 387-403, 1995.

[70] K. E. Grossmann, K. Grossmann, and A. Schwann, Eds., Capturing the Wider View of Attachment: A Reanalysis of Ainsworth's Strange Situation, Cambridge University Press, New York, NY, USA, 1986.

[71] G. Spangler and K. E. Grossmann, "Biobehavioral organization in securely and insecurely attached infants," Child Development, vol. 64, no. 5, pp. 1439-1450, 1993.

[72] J. M. Braungart and C. A. Stifter, "Regulation of negative reactivity during the strange situation: temperament and attachment in 12-month-old infants," Infant Behavior and Development, vol. 14, no. 3, pp. 349-364, 1991.

[73] C. Z. Malatesta, C. Culver, J. R. Tesman, and B. Shepard, "The development of emotion expression during the first two years of life," Monographs of the Society for Research in Child Development, vol. 54, no. 1-2, pp. 1-105, 1989.

[74] B. Renken, B. Egeland, D. Marvinney, S. Mangelsdorf, and L. A. Sroufe, "Early childhood antecedents of aggression and passive-withdrawal in early elementary school," Journal of Personality, vol. 57, no. 2, pp. 257-281, 1989.

[75] J. P. Allen and D. Land, "Attachment in adolescence," in Handbook of Attachment: Theory, Research, and Clinical Applications, J. Cassidy and P. R. Shaver, Eds., pp. 319-335, Guilford Press, New York, NY, US, 1999.

[76] R. A. Isabella and J. Belsky, "Interactional synchrony and the origins of infant-mother attachment: a replication study," Child Development, vol. 62, no. 2, pp. 373-384, 1991.

[77] L. J. Berlin and J. Cassidy, "Relations among relationships: contributions from attachment theory and research," in Handbook of Attachment: Theory, Research, and Clinical Applications, J. Cassidy and P. R. Shaver, Eds., pp. 688-712, Guilford Press, New York, NY, US, 1999.

[78] K. Miyake, S. J. Chen, and J. J. Campos, "Infant temperament, mother's mode of interaction, and attachment in Japan: an interim report," Monographs of the Society for Research in Child Development, vol. 50, no. 1-2, pp. 276-297, 1985.

[79] S. D. Calkins and N. A. Fox, "The relations among infant temperament, security of attachment, and behavioral inhibition at twenty-four months," Child Development, vol. 63, no. 6, pp. 1456-1472, 1992.

[80] N. L. Hazen and M. E. Durrett, "Relationship of security of attachment to exploration and cognitive mapping abilities in 2-year-olds," Developmental Psychology, vol. 18, no. 5, pp. 751-759, 1982.

[81] P. J. Turner, "Relations between attachment, gender, and behavior with peers in preschool," Child Development, vol. 62, no. 6, pp. 1475-1488, 1991.

[82] S. E. Anderson and R. C. Whitaker, "Attachment security and obesity in US preschool-aged children," Archives of Pediatrics and Adolescent Medicine, vol. 165, no. 3, pp. 235-242, 2011.

[83] P. Björntorp and R. Rosmond, "Obesity and cortisol," Nutrition, vol. 16, no. 10, pp. 924-936, 2000.

[84] T. de Vriendt, L. A. Moreno, and S. De Henauw, "Chronic stress and obesity in adolescents: scientific evidence and methodological issues for epidemiological research," Nutrition, Metabolism and Cardiovascular Diseases, vol. 19, no. 7, pp. 511-519, 2009.

[85] R. M. Ganley, "Emotion and eating in obesity: a review of the literature," International Journal of Eating Disorders, vol. 8, no. 3, pp. 343-361, 1989.

[86] M. Michael, "How emotions affect eating: a five-way model," Appetite, vol. 50, no. 1, pp. 1-11, 2008.

[87] L. L. Wilkinson, A. C. Rowe, R. J. Bishop, and J. M. Brunstrom, "Attachment anxiety, disinhibited eating, and body mass index in adulthood," International Journal of Obesity, vol. 34, no. 9, pp. 1442-1445, 2010.

[88] D. R. Pederson, K. E. Gleason, G. Moran, and S. Bento, "Maternal attachment representations, maternal sensitivity, and the infant-mother attachment relationship," Developmental Psychology, vol. 34, no. 5, pp. 925-933, 1998.

[89] I. Bretherton, "The origins of attachment theory: John Bowlby and Mary Ainsworth," Developmental Psychology, vol. 28, no. 5, pp. 759-775, 1992.

[90] A. Susman-Stillman, M. Kalkoske, B. Egeland, and I. Waldman, "Infant temperament and maternal sensitivity as predictors of attachment security," Infant Behavior and Development, vol. 19, no. 1, pp. 33-47, 1996.

[91] W. H. Dietz, "Health consequences of obesity in youth: childhood predictors of adult disease," Pediatrics, vol. 101, no. 3, pp. 518-525, 1998.

[92] C. L. Ogden, M. D. Carroll, L. R. Curtin, M. M. Lamb, and K. M. Flegal, "Prevalence of high body mass index in US children and adolescents, 2007-2008," Journal of the American Medical Association, vol. 303, no. 3, pp. 242-249, 2010.

[93] K. A. Patel and D. G. Schlundt, "Impact of moods and social context on eating behavior," Appetite, vol. 36, no. 2, pp. 111$118,2001$.

[94] U. Bronfenbrenner, "Ecology of the family as a context for human development. Research perspectives," Developmental Psychology, vol. 22, no. 6, pp. 723-742, 1986.

[95] A. P. Kaiser and E. M. Delaney, "The effects of poverty on parenting young children," Peabody Journal of Education, vol. 71, no. 4, pp. 66-85, 1996.

[96] M. L. Diener, M. Angela Nievar, and C. Wright, "Attachment security among mothers and their young children living in poverty: associations with maternal, child, and contextual characteristics," Merrill-Palmer Quarterly, vol. 49, no. 2, pp. 154-182, 2003.

[97] J. Belsky, K. Crnic, and S. Woodworth, "Personality and parenting: exploring the mediating role of transient mood and daily hassles," Journal of Personality, vol. 63, no. 4, pp. 905-929, 1995.

[98] E. Feinberg, P. L. Kavanagh, R. L. Young, and N. Prudent, "Food insecurity and compensatory feeding practices among urban black families," Pediatrics, vol. 122, no. 4, pp. e854e860, 2008. 
[99] A. Drewnowski and S. E. Specter, "Poverty and obesity: the role of energy density and energy costs," American Journal of Clinical Nutrition, vol. 79, no. 1, pp. 6-16, 2004.

[100] N. Olvera-Ezzell, T. G. Power, and J. H. Cousins, "Maternal socialization of children's eating habits: strategies used by obese Mexican-American mothers," Child Development, vol. 61, no. 2, pp. 395-400, 1990. 


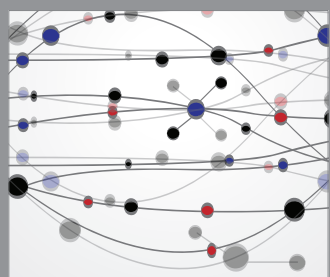

The Scientific World Journal
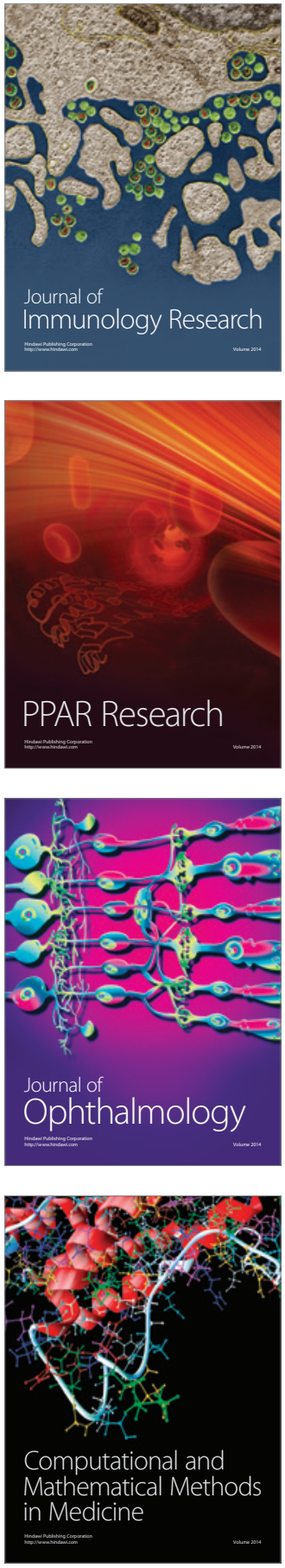

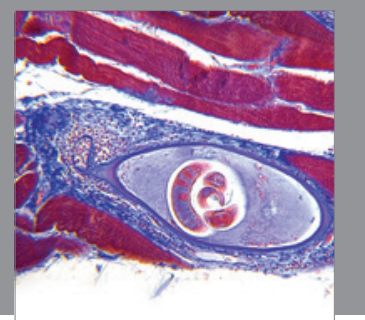

Gastroenterology

Research and Practice
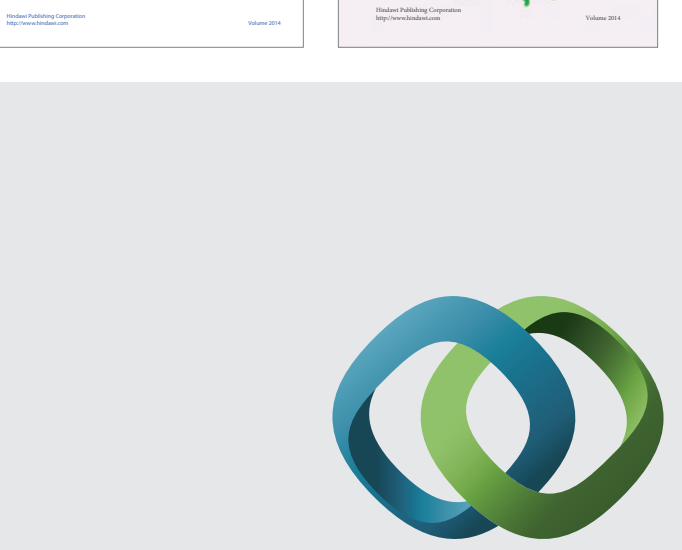

\section{Hindawi}

Submit your manuscripts at

http://www.hindawi.com
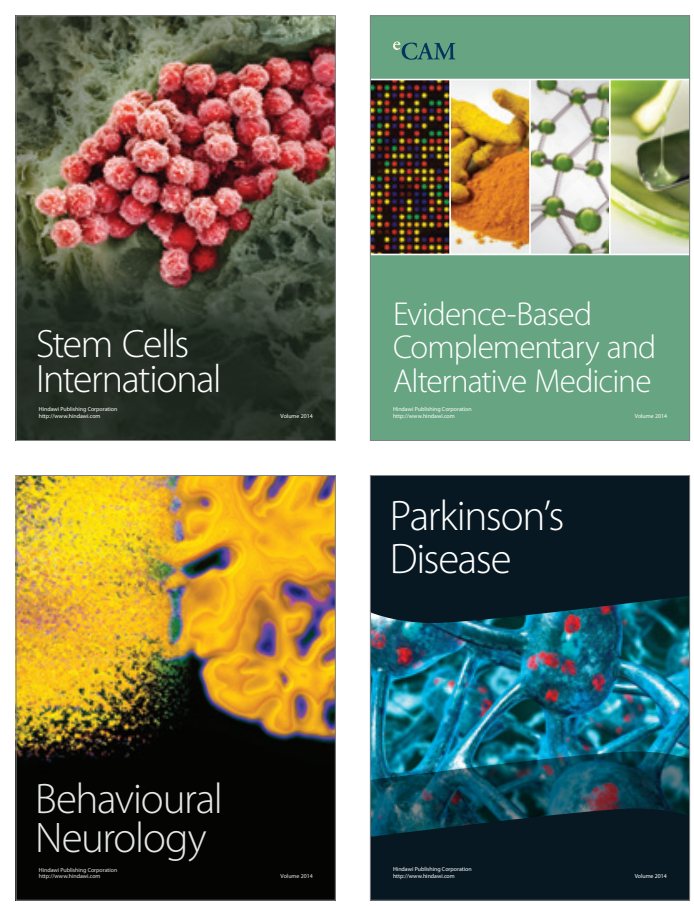

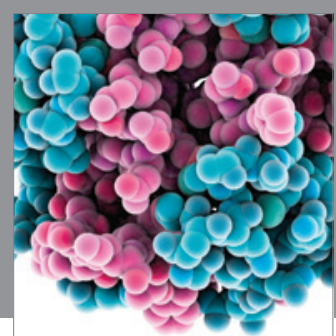

Journal of
Diabetes Research

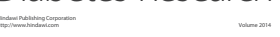

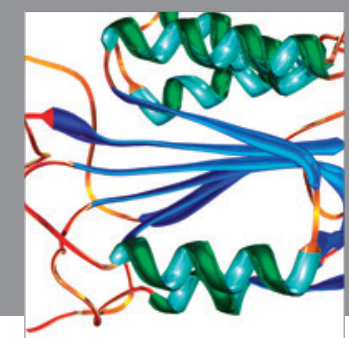

Disease Markers
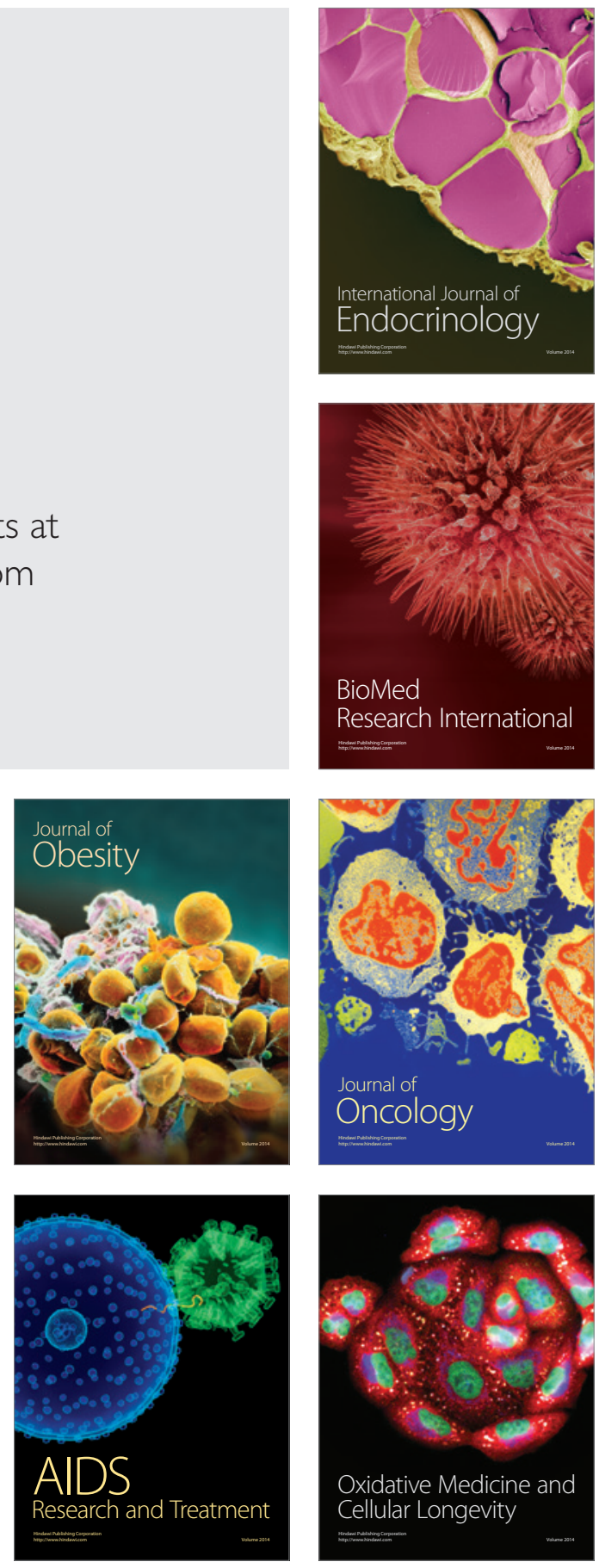